\title{
Social rituals and mental health: evaluation of the Social Rituals Interview Schedule
}

\author{
Aleksandar Janca*1,2, John Owen², Victoria Burbank2, Jane Ventouras², \\ Mohan Isaac ${ }^{2}$ and John Cooper ${ }^{2}$
}

Address: ${ }^{1}$ Royal Perth Hospital, Australia and ${ }^{2}$ University of Western Australia, Australia

* Corresponding author

from International Society on Brain and Behaviour: 2nd International Congress on Brain and Behaviour

Thessaloniki, Greece. 17-20 November 2005

Published: 28 February 2006

Annals of General Psychiatry 2006, 5(SuppI I):SII9 doi:I0.II86/I744-859X-5-SI-SII9

\section{Background}

Social rituals are the routine activities and behaviours comprising the everyday life of those within all communities, such as ways of dressing, communicating, and sleeping. Irregularities in an individual's ritualistic behaviours are usually noticed by his/ her social others, and may be perceived as early signs of impaired mental functioning. This study explored the relationship between disturbances in social rituals and the prodromal phases of mental illness. Via the evaluation of a novel instrument, the Social Rituals Interview Schedule, the project examined the extent to which disturbances in social rituals can be used to identify individuals at risk of mental illness.

\section{Materials and methods}

The Social Rituals Interview Schedule is a semi-structured interview which measures the changes observed during the pre-diagnostic stages of a mental illness with respect to life domains that are representative of universal social rituals. Through a multi-disciplinary approach involving anthropologists and mental health professionals, the instrument was developed and conducted with the relatives/friends of 30 psychiatric patients with various diagnoses.

\section{Results}

Both the kappa values for inter-rater reliability and the percentage of change observed were high across the full range of instrument domains, thus proposing the Social Rituals Interview Schedule as a reliable tool for measuring changes characteristic of prodromal symptoms in psychiatric disorders. The social rituals concept and its accompanying instrument demonstrated clinical usefulness in facilitating the early detection of mental illness and the so the early intervention during the prodromal stages. 